\title{
STANDARDS FOR NURSING DOCUMENTATION IN GENERAL HOSPITALS IN SOUTH AFRICA
}

\author{
L.R.Uys, S.W. Booyens
}

\section{INTRODUCTION AND PROBLEM STATEMENT}

The setting of practice standards for South African nursing has emerged as a research priority since 1985 (SANA). The setting of standards is the first step in quality assurance programmes. The steps of a quality assurance programme usually consists of the following:

1. setting of standards based on values;

2. formulating criteria to measure each standard

developing measuring instruments;

4. measuring the quality of care;

5. identifying problem areas;

6. designing and implementing remedial action;

7. remeasuring the quality of care

(Bruwer, 1987)

In the regulations of the South African Nursing Council it is clearly stated that recording the course of the patient's health problem, the care received and the results of this care, is the responsibility of the registered nurse (Reg. nr. 2598 of 30 Nov 1984). When a project was started in 1987 to develop standards for nursing in general hospitals, it was decided that the recording aspect of practice should be a priority for the following reasons:

1. Most of the available quality assurance instruments are based at least partly on chart reviews. Badly kept records thus makes any quality assurance nrogramme difficult.

Nurses in South Africa have been endeavouring to implement the problem oriented approach to their records, and this has focussed a lot of attention on record-keeping.

3. Some nursing research has shown that this aspect of nursing practice is not of a satisfactory quality (Booyens, 1987).

The objectives of this study were:

1. To formulate standards for all nursing records, valid for all medical and surgical units in all types of general hospitals in South Africa.

2. To design an evaluation instrument based on these standards;

3. To identify factors which influence nursing documentation significantly, and draw up expectancy tables with regard to these factors in order to make comparisons possible.

\section{LITERATURE SURVEY}

There are many indications for the nurse to keep accurate and complete records (Searle, Robertson and Nel, 1985: 256266 ), but the most important is probably

\section{Abstract}

In this project standards for nursing records in general hospitals were formulated and then validated by' $a$ group of nurses. An instrument was then designed to evaluate to what extent the standards are reached in a particular hospital. The instrument was then tested in a sample of nine hospitals. The reliability and validity of the instrument is discussed.

\section{Opsomming}

In hierdie projek is standaarde vir verpleeg-rekordhouding in algemene hospitale geformuleer en daarna deur 'n groep verpleegkundiges gevalideer. 'n Instrument is toe ontwerp om te evalueer tot watter mate die standaarde in 'n hospitaal bereik word. Hierdie instrument is daarna getoets in 'n steekproef van nege hospitale. Die geldigheid en betroubaarheid van die instrument word bespreek.

the association between good patient care and good record keeping. Phaneuf (1976: 48-49) says in this regard that research has shown a positive correlation between the quality of medical records and the quality of medical care, and that this is also true about nursing, since "the conditions that bring about good care are also responsible for bringing about good recording".

Nursing records cover all three phases of the patient's hospitalisation, namely admission, progress and discharge. In a study by Ciuca (1972) on 235 nursing care plans in six hospitals, it was found that $72 \%$ of the recordings dealt with medication, treatment, monitoring of vital signs, intake and output and diagnostic tests, while only $28 \%$ dealt with nursing interventions

Most of the quality assurance instruments currently in use is based at least partially on auditing of records. Phaneuf's audit instrument is a retrospective inspection of a nursing record (1976). Monitor, a British instrument which was based on the American RushMedicus instrument, is a comprehensive list of 220 criteria, which is assessed either through a chart review or interviews or observation (Goldstein e.a. 1983). All these instruments are focused on process standards, as opposed to structure and outcome standards.
TERMINOLOGY:

- Nursing records or nursing documentation is the inscriptions of registered (including students) or enrolled nurses in the patient record during admission, treatment and discharge.

- A standard is a statement describing the expected level of performance against which the quality can be evaluated.

- A criterium is an indicator which is suitable for measuring a standard.

\section{METHODOLOGY:}

The study was carried out in the following steps:

- The formulation of standards for documentation.

- The development of an evaluation instrument.

- The identification of the significant factors influencing nursing documentation.

\section{The formulation of standards for} documentation:

A thorough literature survey was done and three general standards were then formulated, together with the criteria for each.

The three general standards were the following:

a) The document complies with legal requirements.

b) The document is a complete record of the condition of the patient and the nursing care rendered.

c) The document is an effective record of reality.

The Nursing Record Standard Sheet was then presented to two groups of registered nurses from different regions in the country. They were required to evaluate the standards and criteria according to the following questions:

- Is there consensus on the meaning and clarity of each item?

- Is the criterium an acceptable indicator of the standard of care?

- Should any criteria be deleted or added?

- How important do they judge the criterium to be?

The evaluation first took place individually, and was then debated by the group.

This peer group evaluation lead to the wording of many criteria to be amended, criteria being left out because consensus could not be reached on their acceptability, 
and some criteria being added. On the basis of the work of the peer groups, the content validity of the Nursing Record Standard Sheet was accepted.

\section{The development of an evaluation instrument:}

2.1 Instrument: The criteria which had been identified were arranged in the form of a check list which could be used to audit a patient record. In some cases the data in the record had to be validated against other documents, e.g. doctor's notes, flow charts or by questioning the patient.

The instrument was prepared so that the data could be computerised. A small pilot testing of the instrument was done in one hospital.

2.2 Sample: The instrument was tested on a stratified random sample in two regions of the country, as illustrated in Table 1 . In each hospital the wards/units to be used were randomly chosen. In every unit $20 \%$ of the records were randomly chosen to make up a total of $10 \%$ of the total number of beds in each hospital. Intensivecare units, casualty-, outpatient- and midwifery departments and operating theatres were excluded.

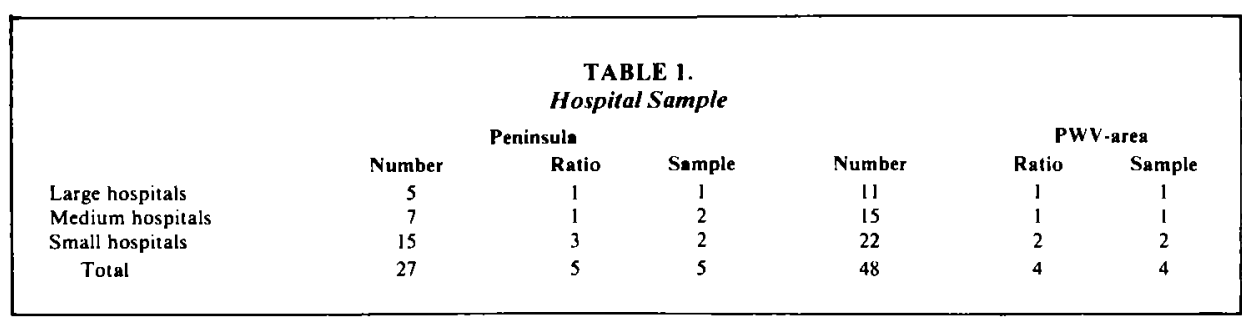

\begin{tabular}{|c|c|c|}
\hline \multicolumn{3}{|c|}{$\begin{array}{l}\text { TABLE } 2 . \\
\text { HOSPITAL DISTRIBUTION }\end{array}$} \\
\hline Hospital & Number of records & $\%$ \\
\hline I. Black academic hospital & 259 & 56 \\
\hline 2. White/other than white academic hospital & 66 & 15 \\
\hline 3. White medium hospital & 29 & 6 \\
\hline 4. White/other than white medium hospital & 23 & 5 \\
\hline 5. White/other than white medium hospital & 20 & 5 \\
\hline 6. White/other than white small hospital & 19 & 4 \\
\hline 7. Private small hospital & 15 & 3 \\
\hline 8. Private small hospital & 15 & 3 \\
\hline 9. White small hospital & 13 & 3 \\
\hline Total & 459 & 100 \\
\hline
\end{tabular}

\begin{tabular}{|c|c|c|c|}
\hline \multicolumn{4}{|c|}{$\begin{array}{c}\text { TABLE } 3 \\
\text { Expectancy Table: Effect of } \% \text { of Registered Nurses on Total Quality of Documentation }\end{array}$} \\
\hline & & \multicolumn{2}{|c|}{ Total quality of documentation } \\
\hline $\begin{array}{l}\text { \% Registered nurses } \\
\text { per unit }\end{array}$ & $\operatorname{Mean}(\mathrm{X})$ & Standard deviation & Norm \\
\hline $0-15$ & 62.85 & 13,83 & $49,02-76,68$ \\
\hline $15,01-20$ & 61,16 & 14,33 & $46,83-75,49$ \\
\hline $20,01-25$ & 60.84 & 13,12 & $47,72-73,96$ \\
\hline $25,01-30$ & 54,30 & 16,59 & $37,71-70,89$ \\
\hline $30.01-35$ & 56,17 & 18.51 & $37,66-14,68$ \\
\hline $35,01-40$ & 68,36 & 14,24 & $54,12-82,60$ \\
\hline $40,01-50$ & 66,94 & 20,51 & $46,43-87,45$ \\
\hline $50+$ & 46.51 & 6,77 (small & $39,74-53,20$ \\
\hline
\end{tabular}

TABLE 4

Expectancy Table: Effect of \% Bed Occupancy on Total Quality of Documentation

\begin{tabular}{cccc}
\multicolumn{3}{c}{$\begin{array}{c}\text { Expectancy Table: } \boldsymbol{E f f e c t} \text { of \% Bed Occupancy on Total Quality of Documentation } \\
\text { Total quality of documentation } \\
\text { \% Bed occupancy }\end{array}$} & \multicolumn{3}{c}{$\begin{array}{c}\text { Norm } \\
\text { Standard deviation }\end{array}$} \\
per unit & & & \\
$0-15$ & 55,15 & 13,95 & $41,20-69,10$ \\
$50,01-60$ & 70,59 & 15,41 & $55,18-86,00$ \\
$60,01-70$ & 64,42 & 13,38 & $51,04-77,80$ \\
$70,01-80$ & 68,45 & 17,41 & $51,04-85,86$ \\
$80,01-90$ & 63,50 & 15,75 & $47,75-79,25$ \\
$90,01-100$ & 62,35 & 15,98 & $46,37-78,33$ \\
$100,01-125$ & 57,96 & 16,86 & $41,10-74,82$ \\
$125,01-150$ & 52,07 & 13,50 & $38,57-65,57$ \\
$150,01-175$ & 44,49 & 13,24 & $31,25-57,73$ \\
$175,01-200$ & 49,18 & 17,56 & $31,62-66,74$ \\
& & & \\
\hline
\end{tabular}

2.3 Field workers: Three registered nurses were used as field workers, after receiving training from the researchers.

\section{Independent variables:}

It was expected that certain important variables might influence the quality of documentation. It was therefore planned to collect information about the following independent variables:

- bed occupancy per unit

- number of registered nurses per unit

- number of other nursing staff per unit

- number of non-nursing staff per unit

- type of unit

- hospital

\section{RESULTS}

\section{Sample description:}

A total of 459 records from nine hospitals were audited (table 2). The sample included private and Provincial hospitals of all sizes, and serving different population groups. From the total of 459 records, $27,7 \%$ (127) of the records came from medical units, $29,4 \%$ (135) from surgical units, $14,6 \%(67)$ from paediatr units, and the rest from other general units.

\section{Validity:}

- Content validity. This was accepted since the instrument was based on valid standards and criteria.

- Construct validity. It can be assumed that the quality of nursing documentation will vary with both the bed occupancy of a unit and the staffing levels. This construct was tested with the Nursing Record Standard Sheet (NRSS) and a significant difference $(p=0,000)$ was found between the quality of documentation as measured by the NRSS and these two variables, using a Chi-square correlation analysis. This could be seen as support for the argument that the NRSS is a valid measure of the quality of nursing documentation.

\section{Reliability:}

Inter-rater reliability was calculated on $\mathbf{3 0}$ records that were audited by two field workers. The Chi-square correlation could only be calculated for 40 items, and a correlation of between $p=0,7970$ and $p=$ 1,000 was found for $70 \%$ of these items. On only three items were a low correlation $(p=0,05)$ found. These items required the field workers to count things like the number of notations and the number of signatures over many pages. In the final instrument these items were changed to limit the counting, and so increase the reliability.

\section{The identification of the significant} factors influencing nursing documentation: It was found that the following three variables made a significant difference $(p=$ 0,000 by means of Chi-square analysis) to the quality of documentation:

- the percentage of registered nurses per unit

- the percentage of non-nursing support staff per unit 
- the bed-occupancy rate per unit

The effects of the percentage of registered nurses and the bed-occupancy are summarised in Tables 3 and 4 in the form of expectancy tables. These tables can be used by users of the NRSS to allow for these variables when interpreting results from their own settings.

The influence of the hospital in which the documentation was done, was calculated through an ANOVA and was found to be highly significant $(\mathrm{p}=0,000$ with $F=29,922$ with 458 degrees of freedom). The total quality of the documentation in the different hospitals is given in Table 5. It is interesting to note that the two hospitals which had an average documentation quality of less than 3,00 (hospitals 3 and 8 ), were the only private hospitals in the sample. The next lowest, hospital 1 with 3,02 , is a large Black hospital with a much higher bedoccupancy rate and lower staff numbers than hospitals 3 and 8 .

\begin{tabular}{|c|c|c|}
\hline \multicolumn{3}{|c|}{$\begin{array}{l}\text { TABLE } 5 \text {. } \\
\text { Quality of Record Keeping for } 9 \text { Hospirals on a 6-point } \\
\text { Scale }\end{array}$} \\
\hline Hospital & $\begin{array}{c}\text { Quality of } \\
\text { documentation }\end{array}$ & $\begin{array}{l}\text { Number of records } \\
\qquad(N=459)\end{array}$ \\
\hline 1 & 3,02 & 259 \\
\hline 2 & 3,91 & 23 \\
\hline 3 & 1,93 & 15 \\
\hline 4 & 3,69 & 13 \\
\hline 5 & 4,63 & 19 \\
\hline 6 & 5.52 & 29 \\
\hline 7 & 5,40 & 20 \\
\hline 8 & 2,40 & 15 \\
\hline 9 & 4,38 & 66 \\
\hline Total & - & 459 \\
\hline
\end{tabular}

The type of unit also made a significant difference $(p=0,000)$ to the quality of documentation (ANOVA: $F=5,104$ with 458 degrees of freedom), but the influence is difficult to interpret (see Table 6).

\begin{tabular}{|lcc|}
\hline \multicolumn{3}{c|}{ TABLE 6. } \\
Unit & Quality of Documentation per Unit \\
& Total Quality & Number of records \\
& $($ N $=459)$ & $(27$ \\
Medical & 55,11 & 135 \\
Surgical & 60,79 & 67 \\
Paediatric & 61,81 & 28 \\
Gynaecological & 58,17 & 52 \\
Orthopaedic & 61,28 & 41 \\
Mixed general & 68,40 & 3 \\
Rehabilitation & 74,92 & 6 \\
Oncology & 80,18 & 459 \\
Total & - & \\
\hline
\end{tabular}

\section{CONCLUSION}

The Nursing Record Standard Sheet seems to be a reliable and valid instrument for measuring the quality of nursing documentation.

It is also obvious from this research that numbers of registered nurses and nonnursing support staff, as well as bedoccupancy rate, type of unit and type of hospital influence the quality of nursing documentation significantly.

The instrument, its cue sheet and instructions for administering it is available at the publication section of the SA Nursing Association.

Although this instrument evaluates only one aspect of the practice of nurses in general hospitals, it should be a useful tool in the hands of nurse administrators.
References

Bruwer, A. 1981 Quality control in nursing. Unpublished D. Cur dissertation, UPE.

Booyens, S.W. 1987. Die toepassing van die wetenskaplike metode in verpleging in sekere Suid-Afrikaanse hospitale - gehalle evalueringsperspektief. Unpublished D. Litt. et Phil dissertation, UNISA.

Ciuca, R.L. 1987. Over the years with the nursing care plan. Nursing Outlook, 20 (11): 706-711.

Goldstone, L.A., Ball, J.A., Collier, M.M. 1983 Monitor, an index of the quality of nursing care for acute medical and surgical wards 2nd ed. Newcastle Upon Tyne, Newcastle Upon Tyne Polytechnic.

Paton, F. 1986. Priority areas for nursing research. Curationis 9 (2): 13-14

Phaneuf, M.C. 1976. The nursing audit: selfregulation in nursing practice. New York: Appleton-Century-Croft.

Searle, C., Robertson, B. and Nel, C.M. 1985. Verpleeg-administrasie: Studiegids I vir NUAI00-L. Pretoria: UNISA

This research was supported by a HSRC grant. We want to thank the following people for their assistance at different stages of the research:

Mrs L. Coetzee, $\operatorname{Dr} A$. Bruwer, Dr C.W. Fölcher and Miss A. van Bruggen.

L.R. Uys D.Soc.Sc., R.N., R.M., P.N. D.N.A., D.H.A

Professor and Head, Department of Nursing. University of Natal

S.W. Booyens, D. Litt et Phil (UNISA)

R.N., R.M., Dip. Intensive Care

Associate Professor, Department of Nursing. University of South Africa. 